\title{
On the Gastro=Motor Effect of Stimulating the Dorsal Roots of Toads. $\$$
}

\author{
By \\ Kenzo Hasimoto. \\ (橋 本 然 藏) \\ (From the Physiological Laboratory of Prof. I. S'atake, \\ Tohoku Imperial University, Sendai.)
}

Now that stimulation of the dorsal spinal root produces the vasodilatation has been generally recognized, at last after rejection and oblivion of several years, it seems worthy of reinvestigating a similar question, that is, the viscero-motor effect of stimulating the dorsal roots.

While this question was first treated and repeatedly answered in the affirmative sense in the Laboratories of E. Hering, ${ }^{1)}$ - Langley with his co-workers ${ }^{2}$ repeatedly refused to accept it, as in the case of the vasodilatation problem. They came however finally to recognize this as well known.

The present investigations were performed to see whether or not the viscero-motor problein should share its fate with the other.

Stein ach worked on very large frogs (rana esculenta) and Hungary frogs, whereas the investigations in Cambridge were done commonly on English frogs (commonly rana temporaria) besides some head of frogs sent from Steinach.

In the present researches the bufo formosus Baulenger was used of similar size to the animals of Steinach.

It may be noted that a similar question was investigated in cases of mam-

§) Read before the eleventh Jap. Physiol. Meeting, March 1932 (Jap. J. of Med. Sci., III. Biophysics, 19(31-) 33, 2, 269**).

1) Steinach, Lotos, Cit. in Ctrlbl. f. med. Wiss., 1893, 31, 861; Steinach with Wie ne r, Plügers Arch., 1895, 60, 593; S te in a c h, Ibid., 1898, 71, 523 \& S z y manowsk i, Ibid., 554; Hof m a n n, Ztrlbl. f. Physiol., 1901-2, 15, 741.

2) Horton-Smith, J. of Physiol., 1897, 21, 101 ; Dale, Ibid., 1901(-2), 27, 350; $\mathrm{L}$ angley and $\mathrm{Orbeli,} \mathrm{Ibid.,} \mathrm{19(10-)} \mathrm{11,} \mathrm{41,} 473$. 
mals by K uré, Iziko and Is hikawa $a^{3)}$ on the one hand, and by $\mathrm{Hukuhara}{ }^{4}$ on the other.

\section{Methods.}

Some precautions advised by previous writers ${ }^{100}$ being taken into consideration, the experiment was carried out only in autumn, and usually on toads freshly taken. But sometimes animals kept for a while in a wooden box having clay on its bottom were utilized and occasionally they were fed on flies, earth worms and other insects. The room temperature was $12^{\circ}-27^{\circ}$.

One day before the stimulation experiment, the spinal cord was laid bare in the whole length, care being taken not to injure the dura mater and to avoid bleeding as far as possible. Then the wounds were sewed up. Next day, the toad having been placed on its belly, the spinal cord was again uncovered, the skin was cut transversally on the left side at the level of the fore and hind limbs, and the muscle layers lateral from the spinal column were cut through longitudinally, followed by the incisions done in the same manner to the skin. The parts of skin and muscle layers were then pinned on the wooden plate, on which the animal was fixed. The left lung which then protruded from the incision opening, was shrivelled by a puncture, and the stomach was drawn out on the peritoneal surface of the muscle layers. It is prevented from drying further by dropping the saline solution from time to time.

The dura mater was then carefully opened and a ligature with a fine silk-thread tied the dorsal root as close as possible to the spinal cord and the nerve divided between the cord and the ligature. Then a cut was laid between the medulla ablongata and the spinal cord, and the medulla oblongata and the brain were pithed.

When the stomach was taken out from the incision opening spontaneous movements were observable. Circular contractions occurred one after another with an interval of one minute or more. Sometimes peristaltic movements were visible, travelling through from the cardia to the pylorus.

Stimulation was carried by means of du Bois Reymond's apparatus; induction currents with the coil distance of $13 \mathrm{cms}$. being. perceptible to the tongue.

3) K u ré, Gurentugebiito, 1930, 4, 1127 ; I z i k o, Tokgo Igaku Zassi, 1931, 45, 1239 (With German abstract); Ishikawa, Ibid., 1932, 46, 616 (With English abstract); Kuré, I chik o and Ishik a wa, Quart. J. of Exp. Physiol, 1932, 21, 1. 24, 37.

4) H a k hara, Nissin Igaku, 1933-4, 23, 785; Quart. J. of Exp. Physiol., 1934, there).

A i k a wa, Jap. J. of Med. Sci., III. Biophysics, 1931, 2, 91 (Previous references 


\section{Experimental Data.}

On excluding the medulla oblongat a in the stomach, some strong peristalsis or contractions occurred; but one must wait for their subsidence, a matter of several minutes, before beginning the stimulation. As described by Langley and Orbeli, ${ }^{2}$ the effect of stimulation begins with a long latency and disappears with a long after effect, so that two stimulations must be separated at least by some five minutes. And contractions definitely more marked than the spontaneous movements in the preceding one can only be taken as an indication of effectiveness of stimulation.

The stimulation was continued for about $20-30$ seconds as a rule, then contractions set in usually just after the end of stimulation if it be effctive.

Third dorsal roots: Effect of stimulating the third doasal root was variable and decidedly weaker than that of the fourth roots. The coil distance was taken as from 8 to $14 \mathrm{cms}$. apart. The stimulation induced contractions in the cardia and the lower part of the oesophagus, but never in the corpus. Either circular or peristaltic contractions were observed. The left root was effective in 26 cases and noneffective in 3 cases, and the right root effective in 21 cases and noneffective in 8 cases. In two toads both the sides roots were noneffective. In one or two instances one side root had no effect. In 10 cases of the left dorsal root and in 10 cases of the right, contractions occurred mainly in the lower portion of the oesophagus, and in the remaining cases (Left: 16 cases and right: 11 cases) mainly in the cardia. In a little larger number of cases the contractions were of a rather peristaltic nature (Left: 15, Right 11).

Fourth dorsal roots: These roots were effective in causing a very strong peristaltic wave and occasionally circular contractions in the corpus, the cardia and pars pyloricus. On stimlating the left root they were observed chiefly in the cardia in 10 cases, in the corpus in 14 cases and in the pars pyloricus in 4 cases, and in the case of the right root, the figures were 3,16 and 7 respectively. Only in two cases antiperistalsis was observed. At times one side root had no effect, and we had two toads in which both the side dorsal roots proved entirely non-effective.

Fifth dorsal roots: Only in 4 toads out of 30 these roots brought about circular contractions in the pars pyloricus. Sixth dorsal roots had no motor effect upon the stomach at all.

After all we failed to detect any motor effect on the stomach and lower part of oesophagus by stimulating the dorsal roots from the 
third to the sixth in 9 toads out of 40 , which were the total number of animals utilized in the present investigations.

Furthermore we failed to find any effect at all by stimulating the ventral roots, the third ventral roots in 28 toads, the fourth in 30 , the fifth in 29 and the sixth in 26 specimens.

It is thus proved that the third, the fourth and the fifth dorsal roots, particularly the fourth roots evoke movements in the stomach when stimulated, in accordance to the old findings in old Hering's Laboratory.

The negative outcome of stimulating the ventral roots is also agreeable to $\mathrm{H}$ or t on-S m it $h,{ }^{2)}$ while viscero-motor effect of the spinal nerves and the rami communicantes has been well established. ${ }^{6)}$ If then it be denied to accept that the dorsal roots convey the impulses to the destinated tissues, whence are the spinal nerves and the rami supplied with the fibres carrying these impulses? This was authentically discussed at length by Steinach.

The nervous fibres transmitting the motor impulses to the stomach of frogs and of toads are reported by the previous observer's ${ }^{6}$ are follows; the hypoglossus being taken as the first root as done in the present communication.

Gastro-motor effect was seen by Waters ${ }^{6}$ in frogs on stimulating the fourth spinal nerve, Ste in $\mathrm{c} \mathrm{h}^{\mathrm{l}}$ ) in the rana esculenta and Hungary frogs on stimulating the third, fourth (most effective) and fifth(seldom)dorsal roots, Dix on in frogs on stimulating the third, fourth (most effective) and fifth rami comm.,

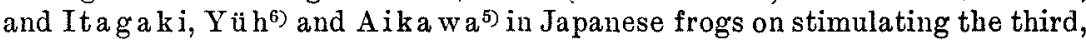
fourth and fifth rami comm. Langley and $\mathrm{Orbeli} \mathrm{i}^{2}$ saw contractions of the whole region of the gut on stimulating the II, III, IV and V spinal nerves.

\section{Summary.}

On working with the toad, bufo formosus Baulenger, the dorsal spinal roots, the third, fourth and fifth, were stimulated with the motor effect upon the stomach and the lower part of oesophagus. No narcosis was used, and the section was carried out between the medulla oblongata and the spinal cord. The corresponding ventral spinal rcots had no effect at all.

The present investigations therefore designate to revive the view that the dorsal roots carry viscero-motor impulses, which apparently nearly died out through rejection by the Cambridge physiologists, just as did the vasodilator problem.

6) Wa ters, J. of Physiol., 1885, 6, 460; Dix o n, Ibid., 1902, 28, 57; L a, ng le $y$ and Orbeli (2); Itagaki, Jap. J. of Med. Sci., III. Physiology, 1930, 1, 105; Yüh, Ibid., $1931,2,25 ; \mathrm{A} i \mathrm{k}$ a wa (5). 